\title{
Heart Failure with Normal Ejection Fraction
}

\author{
Meliza Goi Roscani, Luiz Shiguero Matsubara, Beatriz Bojikian Matsubara \\ Faculdade de Medicina de Botucatu - UNESP, São Paulo, SP - Brazil
}

\begin{abstract}
Heart failure with normal ejection fraction (HFNEF) is a complex syndrome that has been broadly studied since the last decade. It is caused by diastolic ventricular dysfunction demonstrated by complementary methods, such as hemodynamic study or echocardiogram, in the presence of a normal ejection fraction (EF). It affects primarily elderly individuals with comorbidities, such as systemic arterial hypertension, coronary failure and obesity. The physiopathological mechanisms are complex and multifactorial, involving the myocardial passive stiffness, the ventricular geometry, the pericardial restraint and the interaction between the ventricles. The main objectives of the treatment were to decrease the pulmonary venous congestion and the heart rate and control the comorbidities. There is no strong evidence that the use of specific medications, such as the angiotensin-converting enzyme inhibitors or beta-blockers can influence mortality. The poorer prognostic factors include advanced age, presence of kidney dysfunction, diabetes, functional class III and IV (NYHA) and advanced-stage diastolic dysfunction, with a restrictive pattern of ventricular filling.
\end{abstract}

Another aspect that has been increasingly cited in the literature is the analysis of the role of the systolic function in HFNEF cases. All these aspects are analyzed in detail in the present review.

\section{Introduction}

Heart failure (HF) is a complex syndrome characterized by intolerance to physical exertion, fluid retention and congestive phenomena, which after symptom onset, presents high rates of morbimortality.

Its prevalence is increasing worldwide and it is estimated that there will be 5 million cases of HF in Brazil by the year $2025^{1}$. The accumulated risk of developing HF during a

\section{Key words}

Heart failure; diastole; cardiomegaly; echocardiography; compliance.

\footnotetext{
Mailing address: Meliza Goi Roscani •

R. Doutor José Augusto de Arruda Botelho, 70 - Jardim Maria Lu - 17203-030 - Jaú, SP - Brazil

E-mail:meliza10@cardiol.br, meliza10@hotmail.com

Manuscript received July 27, 2009; revised manuscript received September 04, 2009; accepted September 21, 2009.
}

decade is higher in the elderly population than in younger individuals ${ }^{2}$. Therefore, in elderly individuals with classic signs or symptoms of HF, the intolerance to physical exercises is frequently due to the increased pressure in the left atrium, although the EF remains within the normal limits.

This condition corresponds to diastolic heart failure (DHF). This entity has been the subject of discussion in the last decade and several concepts have been updated, justifying the present review.

\section{Terminology}

There is a controversy in the literature regarding the most adequate terminology for this clinical condition: "diastolic heart failure" or "HF with normal ejection fraction". Those who defend the term "HF with preserved systolic function" assert that this more descriptive form prevents confusion or a misdiagnosis, considering that the diastolic dysfunction is present in almost all cases of $\mathrm{HF}^{3}$.

The authors that defend the term "diastolic dysfunction" assert that, by specifying the term "diastolic", it is implicit that a significant systolic dysfunction is excluded and that the congestive phenomenon depends on the diastolic dysfunction (DD). They also state that the term "heart failure with preserved systolic function" does not allow the differentiation from cases with mitral valvulopathy with normal EF and that the HF is not due to the diastolic dysfunction ${ }^{4}$.

Currently, several authors have substituted the term "preserved systolic function" by "normal EF", understanding that patients with diastolic HF can present some degree of systolic dysfunction. In the literature, these terms are used as synonyms. This review will use preferentially the term "HF with normal EF", or HFNEF, as it is more descriptive.

\section{Historical aspects and concepts}

According to Roelandt, the first association between myocardial relaxation and ventricular function was described in 1923 by Yendell Handerson, who affirmed that the myocardial relaxation was as important as its contraction ${ }^{5}$. He exemplified that an elderly patient, with delayed myocardial relaxation, could present intolerance to physical exertion. Therefore, what would later be described as heart failure with normal ejection fraction (HFNEF) had just been described.

However, the concept only received attention in the $60 s^{6}$ and the in the following decade, with studies associating myocardial ischemia with left ventricular (LV) diastolic dysfunction ${ }^{7,8}$.

In 1984, Brutsaert described his theory on the triple control of myocardial relaxation ${ }^{9}$, which would depend on pre-load, 
on muscle inactivation and the uniformity of the inactivation in time and space.

Gaasch defined the term "diastolic dysfunction" in 1994, as the "inability of the heart to accommodate the blood volume during diastole at low pressures; the ventricular filling is delayed or incomplete and the atrial pressure increases, causing pulmonary or systemic congestion"10. Ten years later, in 2004, the same author ${ }^{11}$ redefined the entity, writing: "The diastolic dysfunction can occur regardless of whether the EF is normal or abnormal. If the patient with normal EF develops intolerance to physical exertion, dyspnea and congestion, it is necessary to use the term "Diastolic Heart Failure".

Researchers have asserted that DHF would really be the clinical manifestation of a transient systolic dysfunction, secondary to ischemia or hypertension. To refute this assertion, Baicu and cols. evaluated patients with a diagnosis of DHF and individuals without ventricular dysfunction through LV manometry associated with the calculation of the ventricular volume ${ }^{12}$. All indices of global systolic function and myocardial contractility were preserved in patients with DHF. The authors concluded that, even in the presence of slight alterations in the systolic function, the term DHF is applicable, considering the evident contribution of diastolic dysfunction in the HF condition.

\section{Epidemiology}

Among patients with the clinical HF syndrome, the prevalence of HFNEF varies broadly in the different studies, from $40 \%$ to $71 \%$, with a mean of $56 \%{ }^{13}$. This variation is probably due to the definition adopted for the term "preserved systolic function" and the characteristics of the studied population, such as age, ethnicity and prevalence of the female sex. For instance, two studies published 2000, one developed in the North-American population and another in the European population, used three categories of systolic function: preserved, slightly decreased and moderately or severely decreased. However, in the American study, the systolic function was considered preserved when EF $\geq 0.50$ and corresponded to $24 \%$ of the patients ${ }^{14}$; in the European study the $\mathrm{EF} \geq 0.45$ was considered preserved and corresponded to $38 \%$ of the patients ${ }^{15}$. Another aspect is the fact that some studies grouped together patients with normal or slightly decreased $\mathrm{EF}^{16}$.

Regarding age, it is known that the prevalence of HFNEF is directly associated with this variable ${ }^{4}$. A population study including individuals older than 45 years described a prevalence of $\mathrm{HF}$ of $2.6 \%$. Of these individuals, $41 \%$ presented $\mathrm{EF}>0.50^{17}$. Similar results were found in subsequent publications ${ }^{18-20}$. In elderly populations aged 70 or older, the prevalence can reach $50 \%{ }^{21}$. Finally, series of patients with HF and a predominance of the female sex can present rates of preserved EF with frequencies as high as $60 \%{ }^{22}$.

\section{Physiopathology}

The ventricular filling in diastole is defined by the physical characteristics of the chamber, which establish the relations between pressure and volume. These physical characteristics are coordinated by the ventricular compliance that describes the ratio between a given variation in volume and its corresponding variation in pressure ${ }^{23-27}$. Although these concepts are applicable to both ventricles, the left ventricle (LV) will be used as reference to facilitate comprehension.

The compliance must be analyzed, considering a given ventricle, at the end of the diastolic filling, after the atrial contraction, when all active phenomena of diastole are, in theory, complete (Figure 1). At this exact moment of the cardiac cycle, if the ventricle operates under different loading conditions, the points of pressure-volume association show a characteristic curve in the Cartesian plane, typical of an exponential function.

The first clinical implication of this characteristic is that in a given ventricle containing little volume, significant additional increases in volume are tolerated, with no pressure variation. However, after a certain limit, small increases in volume would cause significant variations in diastolic pressure. That is, a same ventricle can present variable compliance, depending on the volume at which it operates ${ }^{25}$.

The second implication is that small ventricles hold lower volumes, whereas large ventricles can contain higher volumes at low pressure. Figure 2 shows the schematic diagram of the deviations of the curve of compliance in pathological situations. In concentric hypertrophy, for instance, there are more marked variations of pressure for a given variation of volume, even within the limits considered to be normal. In these cases, the patient shows a tendency to develop venous congestion, even though the EF is preserved. On the other hand, in dilated chambers, when the curve is shifted to the right, the diastolic pressure will reach high values only when there is excess volume. That is what happens in

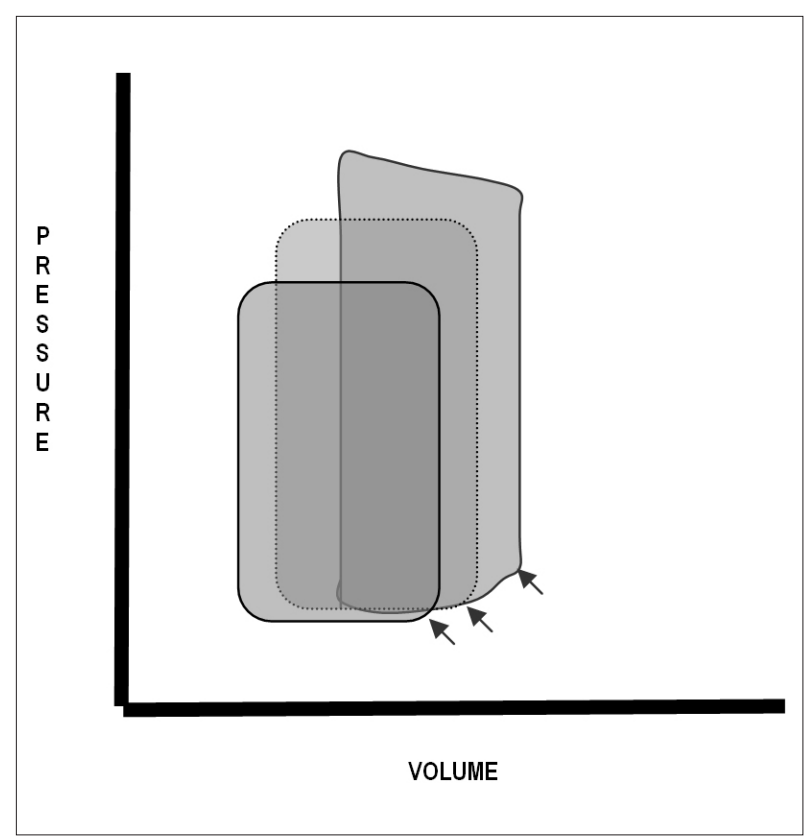

Figure 1 - Schematic representation of $L V$ pressure-volume loops occurring in a hypothetical situation, in three different load conditions. The arrows indicate the points in the diagram that correspond to the end of the diastole. These points comprise the characteristic left ventricular compliance curve. 


\section{Review Article}

systolic dysfunctions, when the residual volume in the cavity is increased ${ }^{23,25}$.

The diastole comprehends four phases: isovolumetric relaxation, rapid ventricular filling, diastasis and atrial contraction. During the isovolumetric relaxation there is no ventricular filling. The phase of rapid filling goes from $70 \%$ to $80 \%$ of total ventricular filling in normal individuals and depends directly on the atrioventricular pressure gradient. The diastasis is the phase in which the atrial and ventricular pressures are practically the same and the mitral transvalvular flow corresponds to only $5 \%$ of the total flow. The diastasis can be understood as the functional reserve that guarantees the ventricular filling, in spite of variations in heart rate. That is, in case of tachycardia, the period to be consumed would be the diastasis. Thus, within certain limits, the filling would not be impaired. The atrial contraction contributes with 15\% to $25 \%$ of the diastolic volume and, in physiological situations, courses with the maintenance of the mean atrial pressure.

Within the physiological limits of heart rate variation and considering these four phases of diastole, the factors that affect ventricular compliance and are associated with HFNEF are: myocardial passive stiffness, ventricular geometry, pericardial restraint and interaction between the ventricles.

\section{Myocardial passive stiffness}

The myocardial passive stiffness also corresponds to a mechanical property and describes the necessary force to be applied to the muscle to produce a given deformity. Thus, according to this physical concept, the myocardium is an inert material, with a physical characteristic that depends intrinsically on its composition and not on the active process of relaxation ${ }^{27}$.

However, biologically, the altered relaxation can increase the myocardial passive stiffness, as it is not completed. That

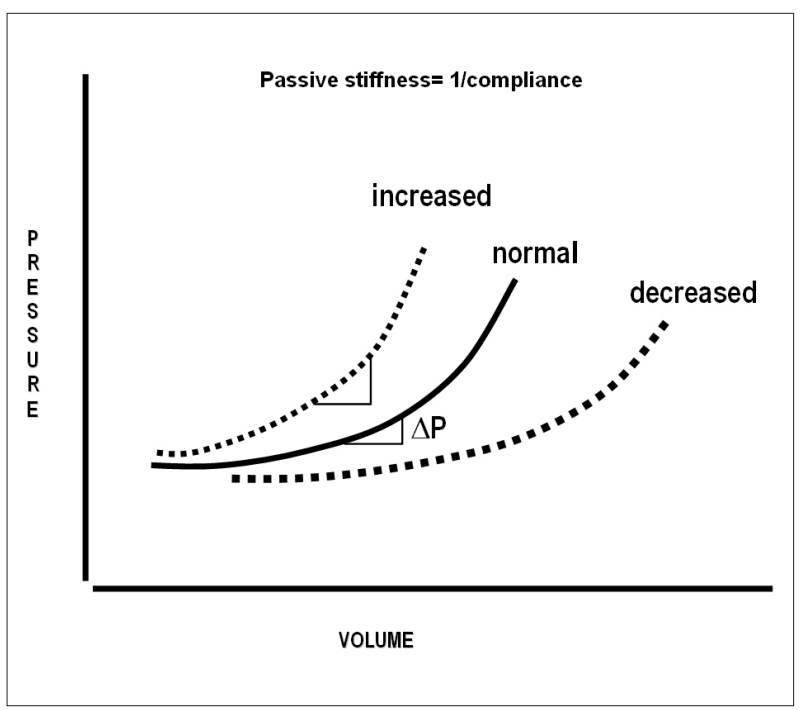

Figure 2 - The typical exponential curve shifts to the left when compliance is decreased. In cases of increased compliance, the shift is to the right. For one given ventricular volume variation, the diastolic pressure $(P)$ increases as a function of the compliance. The passive stiffness of the chamber is the inverse property of compliance. is, at the end of the diastole, with the muscle still partially contracted, it behaves as a more rigid material. Another relevant aspect is the case of myocardial relaxation that shows only delay. In theory, this alteration should not impair the ventricular compliance, or cause HF. However, if there is tachycardia and diastasis suppression, the slower relaxation can behave as an incomplete relaxation and the ventricular filling will occur at elevated pressure, which can cause congestive phenomena. This is one of the explanations of why patients with HFNEF cannot tolerate increases in heart rate.

In brief, one can affirm that the myocardial passive stiffness depends on the relaxation and the muscle composition.

\section{Myocardial relaxation}

The myocardial relaxation requires energy expenditure and starts at the final phase of systolic ejection. This process influences mainly the initial phases of diastole. In normal hearts, even during physical exercise, the process is completed in this period. The release of catecholamines accelerates the relaxation of myocardial fibers, maintaining the low diastolic pressure, in spite of the tachycardia and the increased venous return.

It is the myocardial relaxation that generates the pressure gradient between the left atrium (LA) and the LV, without an additional increase in the left atrial pressure, preventing pulmonary congestion ${ }^{24}$.

The relaxation depends mainly on the ATP supply and the intracellular calcium homeostasis. The inadequate function of several proteins involved in calcium homeostasis can also deeply affect the relaxation process ${ }^{28}$.

In cases of delayed LV relaxation in which there is maintenance of the left atrial pressure, there is a decrease in the atrioventricular pressure gradient and the rapid filling time is prolonged. As a consequence, there is a decrease in the ventricular filling at the initial phase of diastole. At more advanced stages, when in addition to alterations in myocardial relaxation, there is a decrease in ventricular compliance, the pressures in the two chambers, atrium and ventricle, increase, and the patients can present some degree of intolerance to physical exertion. More severe alterations, such as incomplete relaxation and reduced compliance lead to the increase in diastolic pressure to the point of restricting the atrial emptying. In this condition, in general, there are signs that are typical of left HF, such as dyspnea on slight exertion or at rest.

\section{Myocardial composition}

The myocytes occupy around $70 \%$ of the cardiac muscle. In addition to them, there are vessels, fibroblasts and a fibrillar collagen network, with a very complex structure. Although the collagen occupies only $4 \%-6 \%$ of the muscle volume, its high degree of passive stiffness, similar to that of steel, makes small variations in their concentration have significant effects on myocardial passive stiffness ${ }^{29}$.

In cardiac injuries, the mechanical factors lead to the secondary activation of biochemical factors (neurohormonal activation and release of pro-inflammatory cytokines). Among the several effects of these modifications are: the loss of myocytes, the production of tissue metalloprotease inhibitors 
by the endothelium and the production of collagen and collagenases by fibroblasts.

The interaction of these factors determines the concentration of collagen in the myocardial remodeling process.

Considering the myocardial composition, it is not only the collagen alteration that promotes the diastolic dysfunction. The myocardial hypertrophy is another important variable, which signalizes the evolution of the initial cardiac damage to heart failure and cardiovascular (CV) death. In cases of concentric hypertrophy, there is a decrease in the coronary reserve and increased risk of myocardial ischemia, regardless of the presence of coronary atherosclerotic disease, causing the aforementioned relaxation disorders. The change in the ventricular geometry itself can constitute an independent factor of compliance alteration and diastolic dysfunction ${ }^{30}$.

\section{Ventricular geometry}

The eccentric hypertrophy (sarcomere multiplication in series) causes the dilatation of ventricular chamber, resulting in higher tolerance to the volume that reaches the ventricles. In this case, the congestive phenomena only appear when the volume inside the chamber exceeds a certain limit. That is, the congestion and the diastolic dysfunction are secondary to the systolic dysfunction. It is important to understand that the dilated ventricle can behave as a compliant chamber, even though the myocardium presents an abnormal concentration of fibrosis and increased passive stiffness.

The chamber with a concentric geometry has a different behavior because the ventricle is more prone to diastolic dysfunction, regardless of the presence or absence of left ventricular hypertrophy (LVH). From the physical point of view, it is easy to understand that a small-radius chamber with thick walls presents higher resistance to stretching. However, the change in geometry is more complex and extrapolates the physical characteristic. The concentric geometry is associated with significant metabolic changes, functional activation and change in the gene-expression profile of the muscle ${ }^{31}$. All these factors act synergistically to promote myocardial dysfunction.

\section{Pericardial restraint}

The heart is contained inside a rigid structure consisting of collagen that is the pericardial sac. The pericardium has great capacity to adapt to situations of chronic ventricular dilatation, when there is an increase in compliance.

In contrast, in situations of acute dilatation of any of the ventricles, as in some cases of mitral regurgitation and cor pulmonale, the increased diastolic pressure and the occasional pulmonary congestion can present a component of the restraint force imposed by the pericardial sac.

\section{Interaction between the ventricles}

Acute increases in the volume and pressure of one of the ventricles can affect the compliance of the other. However, this interaction is much attenuated in the absence of the pericardium.

\section{Clinical presentation and diagnosis}

The clinical presentation is similar to that of systolic heart failure. It has been described that, in HFNEF, the establishment of dyspnea presents a more acute onset and that the response to the intervention is equally faster ${ }^{32,33}$. In an European study that included hospitalized patients with $\mathrm{HF}$, it was observed that the prevalence of HFNEF was $40 \%$. This entity was associated significantly and independently with the female sex, advanced age and presence of atrial fibrillation (AF). The systolic heart failure was associated with more advanced functional class (NYHA), cardiomegaly, presence of third sound, acute pulmonary edema and left bundle-branch block $^{32}$. Chart 1 shows the differences between HFNEF and $\mathrm{HF}$ with decreased EF.

The HF secondary to DD is currently understood as the entity of comorbidities. Several studies have shown that patients with HFNEF present systemic arterial hypertension (SAH), myocardial ischemia, diabetes mellitus (DM), obesity and thyroid dysfunction. The association with intrinsic heart diseases is less frequent $\mathrm{t}^{34,35}$.

The indices capable of directly quantifying the diastolic function are obtained through invasive procedures. The first one is the tau constant, a broadly used measurement of the rate of $\mathrm{LV}$ relaxation ${ }^{36,37}$. The second direct indicator is the measurement of the ventricular compliance, which requires the simultaneous recording of the pressure and volume of the chamber ${ }^{12}$. The less compliant ventricle is the one that

Chart 1 - Main characteristics of HFNEF and HF with decreased EF

\begin{tabular}{|c|c|c|}
\hline & $\begin{array}{c}\text { Normal ejection } \\
\text { fraction }\end{array}$ & $\begin{array}{c}\text { Decreased } \\
\text { ejection fraction }\end{array}$ \\
\hline \multicolumn{3}{|l|}{ Epidemiology } \\
\hline Female sex & +++ & + \\
\hline Age $>65$ years & +++ & + \\
\hline \multicolumn{3}{|l|}{ Symptoms } \\
\hline Dyspnea & +++ & +++ \\
\hline Angina & +++ & + \\
\hline Acute pulmonary edema & +++ & + \\
\hline \multicolumn{3}{|l|}{ Signs } \\
\hline Third sound & - & +++ \\
\hline Fourth sound & +++ & - \\
\hline Signs of hypervolemia & +++ & ++ \\
\hline Arterial hypertension & +++ & + \\
\hline Atrial fibrillation & +++ & ++ \\
\hline Echocardiogram & +++ & \\
\hline Ejection fraction $<45 \%-50 \%$ & - & +++ \\
\hline \multicolumn{3}{|l|}{ BNP } \\
\hline$>1,000 \mathrm{pg} / \mathrm{ml}$ & + & +++ \\
\hline $400-1,000 \mathrm{pg} / \mathrm{ml}$ & +++ & + \\
\hline
\end{tabular}

Adapted from Arq. Bras. Cardiol. 2009; 93(1 supl.1): 1-71. 


\section{Review Article}

presents a higher increase in pressure for a given volume variation. It is clear that neither index can be used routinely in clinical practice.

The available markers in clinical practice reflect, in fact, a set of variables that indirectly evaluate the diastolic function. Although the most often used indicators for the assessment of diastolic dysfunction are obtained through the echocardiogram, the diagnosis must follow the recommendations of the Brazilian Society of Cardiology for the diagnosis of HF of any etiology ${ }^{38}$. That is, when there is a clinical suspicion of HF, it is necessary to carry out an electrocardiogram, chest X-ray, and, if possible, the BNP measurement. If these laboratory tests show alterations, the echocardiogram is then performed, which will confirm or rule out the diagnosis of HFNEF. It is important to remember that, due to the easy applicability of the examination, the chest X-ray, although not specific, can help to clarify the diagnosis suspicion. That is, when assessing a case of HF, the presence of cardiomegaly increases the chance of systolic dysfunction. On the other hand, is the cardiac area is normal, the probability of HFNEF increases.

The echocardiogram is more accurate and allows the diagnosis of structural alterations, such as hypertrophy and areas of hypokinesis, frequently associated with diastolic dysfunction. The hypokinesis is strongly suggestive of myocardial ischemia, with the deleterious effects on relaxation explaining the association. Moreover, the pulsed Doppler allows the analysis of the transmitral diastolic flow, which originates the primary function indices and the stratification of the dysfunction severity ${ }^{39}$.

As described before, this flow depends on the transvalvular pressure gradient. Under normal conditions, this gradient is maximal immediately after the opening of the mitral valve, considering the plenitude of the left atrium volume and the low intraventricular pressure, due to the myocardial relaxation and the small residual volume in the chamber. At this moment, the flow velocity is maximal, which corresponds to the $E$ wave.

A period of reduced transvalvular gradient follows, with an almost null flow (diastasis). The atrial contraction generates a new gradient and flow, which corresponds to the A wave. The E/A ratio, one of the primary indices for the study of the diastole, remains 1 (Figure 3, A). When the myocardial relaxation is impaired, there is a decrease in the transvalvular gradient in the beginning of diastole, with a decrease in the $\mathrm{E}$ wave. The consequence is an impairment in atrial emptying; the atrial contraction is more vigorous and the A wave increases, decreasing the E/A ratio (Figure 3, B). This flow pattern is characteristic of mild or grade I DD. When there is additional functional impairment, the pressure in the left atrium increases, rebuilding the transvalvular pressure gradients during diastole, although at higher pressure levels and in the presence of symptoms of intolerance to physical exertion. At this stage, the DD is grade II, or moderate (Figure 3, C).

In patients in whom the LV diastolic pressure is high enough to restrict the transvalvular flow during the atrial contraction, the elevated LA pressure allows only an initial high-velocity and short-duration diastolic flow, whereas the flow velocity at the end of diastole being markedly decreased (Figure 3, D). This pattern, called restrictive or grade III pattern, is severe and causes intolerance to slight physical exertion. When the Valsalva maneuver does not bring relief to this alteration,
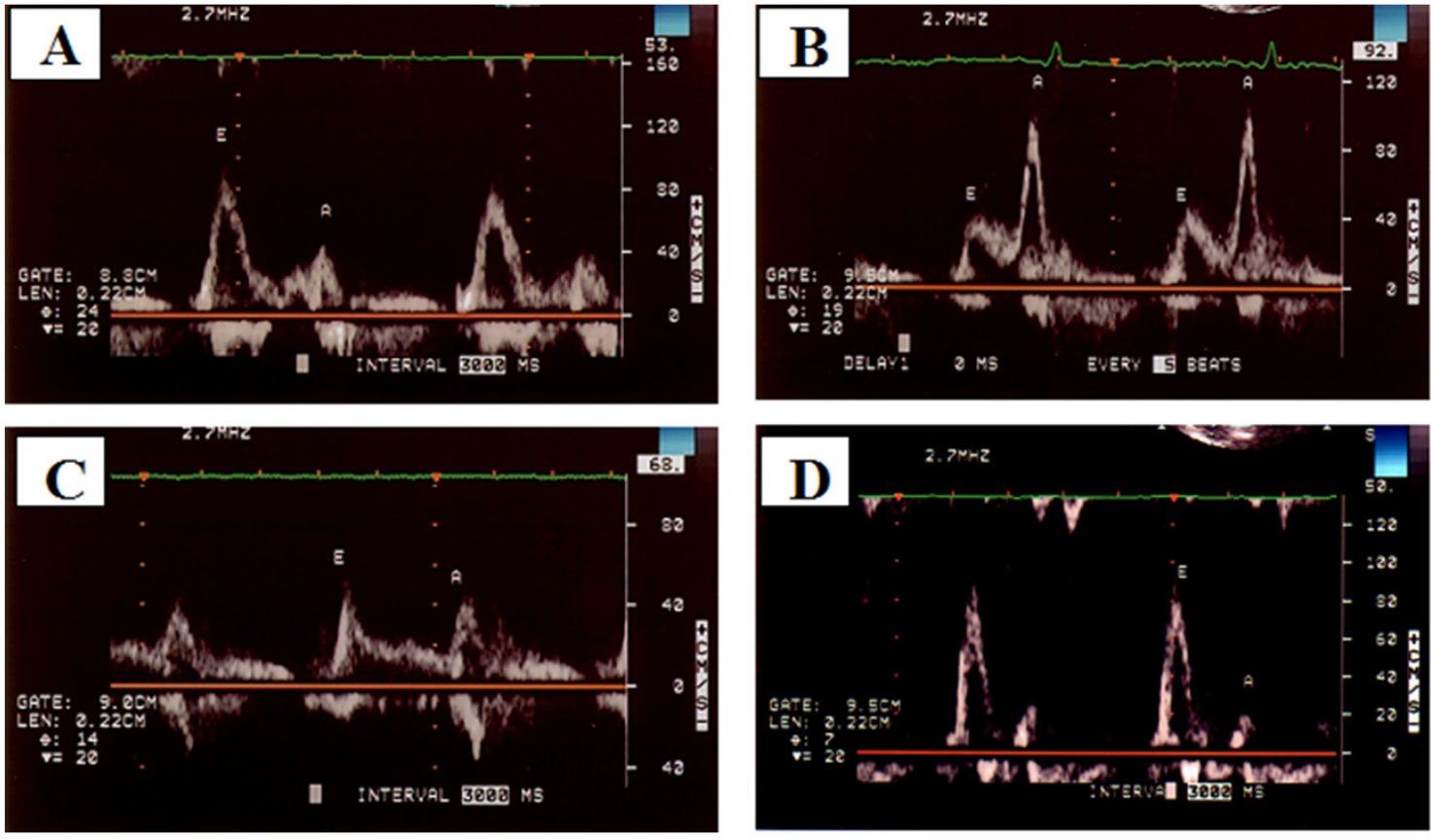

Figure 3 - Diastolic mitral transvalvular flow recorded by pulsed Doppler in a normal individual (A) and in the presence of grade I (B), grade II (C) and grade III diastolic dysfunction (D). 
the DD grade IV is defined, which is also severe. The other two primary indicators derived from the pulsed Doppler are the time of deceleration of the $\mathrm{E}$ wave and the time of isovolumetric relaxation.

The analysis of the flow in the pulmonary veins through the pulsed Doppler allows the indirect assessment of the atrial pressure, which, in the absence of mitral valvulopathy, corresponds to the LV diastolic pressure. In brief, the normal LA pressures allow a constant flow from the pulmonary veins, except during the atrial contraction, when there is a small reverse flow. When this pattern is altered, it is possible to diagnose diastolic dysfunction.

More recently, other important indices have been included in the assessment of the diastolic function, such as the measurement of the mitral annular tissue velocity (tissue Doppler) and the estimate of LA volume and emptying fraction. Currently, these variables, together with the assessment of ventricular volume and myocardial mass, are considered fundamental for the definition of the diagnosis and stratification of the severity of HFNEF ${ }^{15,39}$. It is noteworthy that the European, American and Brazilian recommendations on this topic have incorporated the physiological alterations inherent to aging in the values of the primary indices and those derived from tissue Doppler imaging $14,15,38$. Thus, the accuracy of method to identify higher-risk individuals will be improved.

A relevant aspect to be considered by the clinician that treats patients with HFNEF is the lability of several indices of diastolic function in relation to physical activity. When the examinations are carried out with the patient at rest, there can be a discrepancy between the intensity of the exertional dyspnea and the result of the stratification of the degree of DD. In these cases, the echocardiographic assessment can be carried out immediately after the physical exertion ${ }^{39}$.

The detailed and technical discussion on these indicators is more attractive for the specialist in echocardiography and is not the focus of the present review. However, it is necessary to reinforce the fact that the reliability of the noninvasive indices, especially the flow velocity/mitral annular tissue velocity ratio, to estimate the LV filling pressure remains debatable in the literature ${ }^{40-42}$.

The definitive diagnosis of DD requires three criteria, according to the current concept ${ }^{15}$ : two major ones and a confirmatory one. The unequivocal evidence of DD and the objective evidence of preserved systolic function (EF > 0.50 during the 72 hours of the acute stage of $\mathrm{HF}$ ) constitute major criteria. The objective evidence of DHF constitutes a confirmatory criterion. The objective assessment of the DD could be obtained through the echocardiogram, according to Paulus et $\mathrm{al}^{15}$, or from an invasive direct measurement, according to Vasan and Levy43.

In 2001, Zile et al ${ }^{44}$ evaluated, through cardiac catheterism, the diastolic function of patients with DHF and verified that all of them presented DD. Zile et $\mathrm{al}^{44}$ questioned the need for this third criterion. In 2005, Yturralde and Gaasch ${ }^{45}$ proposed that the two first criteria were considered major ones, as long as the LV size was normal and that the third criterion should be considered only confirmatory, associated to the presence of LVH and increased LA, in the absence of mitral valvulopathy and $\mathrm{AF}^{45}$.

In fact, these indirect signs are being considered more important as DD markers. Pritchett et $\mathrm{al}^{46}$ used the values of the LA volume in more than 2,000 individuals, aged $\geq$ 45 years, included in the study of the County of Olmsted and observed that this variable had a prognostic value in the prediction of 5-year mortality ${ }^{46}$. Lester and cols. defended the position that the LA volume is for $\mathrm{DD}$ as glycated hemoglobin is for $\mathrm{DM}^{47}$.

However, there can be many difficulties in the diagnosis, such as the impossibility to obtain the echocardiogram or unspecific symptoms and little evident signs. The patients often have associated pulmonary disease or are obese; they are elderly individuals with several comorbidities or communication deficit. In conclusion, there are many clinical circumstances that can prevent the direct association between a complaint of physical limitation or dyspnea with a diagnosis of $\mathrm{HF}$.

In these cases, a laboratory marker that can be useful is the plasma level of BNP (brain natriuretic factor). This natriuretic peptide is stored in the ventricular myocardium, being released when the wall undergoes stretching. It is less influenced by the atrial pressure variations and thus, reflects better the ventricular dysfunction than the atrial natriuretic peptide.

Many studies have shown the usefulness of BNP as a diagnostic and prognostic marker in systolic $\mathrm{HF}^{48,49}$. In diastolic $\mathrm{HF}$, the evidence is not so strong, but they have started to appear. The BNP level with the highest accuracy to detect diastolic dysfunction is $60-90 \mathrm{pg} / \mathrm{ml}^{50}$. Additionally, the more severe the dysfunction, the higher the BNP level, which further increases in the presence of clinical signs of HF. The current consensus understands that the BNP level is even more important to rule out the cardiac origin of patients treated for apnea at rest ${ }^{38}$.

\section{Treatment}

Few studies have assessed the clinical outcomes in patients with DHF that were treated with different classes of drugs. And the fact is that none of them showed a change in the natural history of the syndrome.

The first large and well-known study was the CHARMpreserved ${ }^{51}$, published in 2003 and aimed at evaluating the effect of candesartan in 3,025 patients with HF and EF > 40\%. The study population consisted mainly of male individuals and was at an age range that was younger than the one that most often presents DHF. There was no decrease in mortality in this study, although the number of hospitalizations due to HF was significantly lower.

The PEP-CHF ${ }^{52}$ study included older patients, aged 70 years and older and with $\mathrm{EF}>45 \%$ and failed to demonstrate a decrease in mortality with the prolonged use of perindopril. Other studies did not show relevant effects of the use of nebivolol ${ }^{53}$ and digoxin ${ }^{54}$. Recently, the I PRESERVED study, including patients aged 60 years and older with $\mathrm{EF}>60 \%$, demonstrated that the use of irbesartan did not decrease the risk of the compound outcome death and hospitalization due to cardiovascular cause ${ }^{55}$. The TOPCAT study, predicted to 
finish in 2011, intends to assess the effects of spironolactone on the clinical outcomes of 4,500 patients with preserved systolic function.

In this context, currently the main objectives in the treatment of HFNEF are: to control symptoms by reducing the venous congestion and heart rate. The rhythm control is also considered valid in selected patients, either by electrical and/ or chemical cardioversion or sequential pacemaker.

Other objectives to be attained are the control of comorbidities associated with DD, such as the treatment of myocardial ischemia and $\mathrm{SAH}$, prevention and reversal of LV hypertrophy, attenuation or prevention of myocardial fibrosis.

It is necessary to remember that these patients with DD are typically elderly individuals with a normal-sized ventricular cavity. Therefore, drugs such as diuretics and vasodilators can have a disproportional effect on BP. The specific care measures include the monitoring of the BP, kidney function and signs of brain hypoflow. They also include the stimulation to treatment adherence and changes in lifestyle (food ingestion, physical activity and smoking, mainly), considering that these patients are medicated simultaneously with several classes of drugs.

In elderly patients, the conduct must follow some special criteria. It is advisable to start with a certain drug class and gradually add other classes, always one at a time. There is no evidence that the target-dose of each class must be reached, as it occurs in systolic HF. Therefore, it is recommended:

- Start diuretics and beta-blockers with caution;

- If the HF persists, add an angiotensin-converting enzyme inhibitor (ACEI) or angiotensin-receptor blocker (ARB), if there is intolerance to ACEl;

- Add isosorbide dinitrate and hydralazine, if necessary;

- Add calcium-channel antagonists, if necessary;

- Avoid the use of digitalis, in the absence of AF.

Chart 2 summarizes the main therapeutic options and respective levels of evidence in cases of HFNEF according to the III Brazilian Guidelines on Chronic Heart Failure ${ }^{38}$. Note that the levels of evidence for each therapeutic option are not yet high. Therefore, an individualized treatment is important for these patients.

\section{Prognosis}

A study with patients with HFNEF showed that 1-year, 3-year and 5-year survival was, respectively, 84\%, 67\% and $51 \% 32$. In another study the impact of the severity of DD was assessed in 2,042 adults aged > 45 years, with 95\% of them being asymptomatic. It was observed that mortality was significantly higher in those with an echocardiogram result of DD grades II and $\mathrm{III}^{17}$.

These results were similar to the ones described by Pritchett et $\mathrm{al}^{46}$. Moreover, these authors observed that the LA volume presented a prognostic value similar to that of DD severity. In patients with chronic coronary failure, the 3 -year cardiovascular mortality was significantly higher (6\%) in cases with moderate or severe DD, when compared with mild dysfunction $(3.6 \%)$ or normal diastole $(1.1 \%)^{56}$.

Jones et $\mathrm{al}^{34}$ evaluated the 3 -year mortality of a cohort of almost 1,000 patients with HFNEF and EF $>0.45$, who participated in the DIG clinical trial. Among the 18 analyzed variables, the ones that associated with death were: glomerular filtration, NYHA functional class, male sex, advanced age, cardiothoracic index, presence of DM, the need for vasodilators or diuretics. Considering these variables, the patients were assigned risk scores and those with the highest scores $\left(75^{\text {th }}\right.$ quartile) presented a mortality rate of $50 \%$ in the period. Therefore, the patient with HFNEF needs to be assessed through an extensive set of clinical and laboratory variables, which can extrapolate the definition of the degree of dysfunction or of other echocardiographic variables.

\section{Perspectives}

Finally, an aspect that is once more being discussed in the literature is the question regarding the role of systolic dysfunction in HFNEF. In the study by Yu e cols., that included normal patients and patients with DD or systolic HF, it was demonstrated that the systolic function index assessed by tissue Doppler progressively decreased as the diastolic dysfunction degree worsened. This result suggests that patients with

\section{Chart 2 - Guidelines for the treatment of patients with HFNEF}

\begin{tabular}{|c|c|c|}
\hline Class of recommendation & Indications & Level of evidence \\
\hline \multirow{3}{*}{ Class I } & SAH control & $\mathrm{C}$ \\
\hline & Heart rate control in patients with $\mathrm{AF}$ & C \\
\hline & Diuretics to control pulmonary or peripheral congestion & B \\
\hline \multirow{3}{*}{ Class Ila } & $\begin{array}{l}\text { Myocardial revascularization in patients with coronary artery disease undergoing optimized clinical treatment } \\
\text { and symptomatic ischemia or demonstrated at provocative test with adverse effects on cardiac function }\end{array}$ & C \\
\hline & Restoration and maintenance of sinus rhythm in patients with AF to improve symptoms & $\mathrm{C}$ \\
\hline & Treatment with $B B, A C E I, A R B$ for the control of HFNEF, regardless of the presence of $S A H$ or ischemia & B \\
\hline Class Illb & Treatment with CCA for the control of HFNEF, regardless of the presence of SAH or ischemia & $\mathrm{C}$ \\
\hline Class III & Treatment with digitalis to minimize symptoms of HFNEF & $\mathrm{C}$ \\
\hline
\end{tabular}


DD also have systolic dysfunction, albeit without clinical manifestations or with preserved EF.

Another study that used the analysis of ventricular function through the strain rate, identified a direct association between the peak contraction and peak relaxation in normal individuals or with different cardiopathies, suggesting the interdependence of the two phases of the cardiac cycle ${ }^{58}$.

A more recent study, by $\mathrm{Yu}$ et $\mathrm{al}^{59}$, analyzed 56 patients with HFNEF and demonstrated that several echocardiographic indices of systolic function, obtained at rest, were significantly lower when compared to 27 healthy individuals ${ }^{59}$. Furthermore, in the group with HFNEF, these indices did not increase at exercise. This study supports the hypothesis that HFNEF is not a disorder that involves diastole alone, even if the EF is preserved. It also supports the assertions by Lester et $\mathrm{al}^{47}$ : "Perhaps, in a near future, the systolic and diastolic functions will not be clinically interpreted as dichotomous terms. They will be simply understood as cardiac dysfunction".

\section{Potential Conflict of Interest}

No potential conflict of interest relevant to this article was reported.

\section{Sources of Funding}

There were no external funding sources for this study.

\section{Study Association}

This study is not associated with any post-graduation program.

\section{References}

1. Ministério da Saúde. DATASUS. Informações de saúde. [Acesso em 2009 fev. 10]. Disponível em: http://tabnet.datasus.gov.br

2. Ho KKL, Pinsky JL, Kannel WB, Levy D. The epidemiology of heart failure: the Framingham study. J Am Coll Cardiol. 1993; 22 (Suppl A): 6A-13A.

3. Sanderson JE. Heart failure with a normal ejection fraction. Heart. 2007; 93 : 155-8

4. Zile MR, Brutsaert DL. New concepts in diastolic dysfunction and diastolic heart failure: Part II. Circulation. 2002; 105: 1503-8.

5. RoelandtJRTC. On-invasive assessment of left ventricular diastolic (dys) function and filling pressure. Heart Views. 2001; 2 (3): September-November.

6. Parmley WW, Brutsaert DL, Sonnenblick EH. Effects of altered loading on contractile events in isolated cat papillary muscle. Circ Res. 1969; 24 (4): 521-32.

7. Grossman W, McLaurin LP, Rolett EL. Alterations in left ventricular relaxation and diastolic compliance in congestive cardiomyopathy. Cardiovasc Res. 1979; 13 (9): 514-22.

8. Dodek A, Kassebaum DG, Bristow JD. Pulmonary edema in coronary-artery disease without cardiomegaly: paradox of the stiff heart. N Engl J Med. 1972; 286: 1347-50.

9. Brutsaert DL, Rademakers FE, Sys SU. Triple control of relaxation: implications in cardiac disease. Circulation. 1984; 69: 190-6.

10. Gaasch WH. Diagnosis and treatment of heart failure based on left ventricular systolic or diastolic dysfunction. JAMA. 1994; 27: 1276-80.

11. Gaasch WH, Zile MR. Left ventricular dysfunction and diastolic heart failure. Annu Rev Med. 2004; 55: 373-94.

12. Baicu CF, Zile MR, Aurigemma GP, Gaasch WH. Left ventricular systolic performance, function, and contractility in patients with diastolic heart failure. Circulation. 2005; 111: 2306-12.

13. Vasan RS, Larson MG, Benjamin EJ, Evans JC, Reiss C, Levy D. Congestive heart failure in subjects with normal versus reduced left ventricular ejection fraction: prevalence and mortality in a population-based cohort. J Am Coll Cardiol. 1999; 33: 1948-55

14. Kirkpatrick JN, Vannan MA, Narula J, Lang RM. Echocardiography in heart failure. J Am Coll Cardiol. 2007; 50: 381-96.

15. Paulus WJ, Tschope C, Sanderson JE, Rusconi C, Flachskampf FA, Rademakers $\mathrm{FE}$, et al. How to diagnose diastolic heart failure: a consensus statement on the diagnosis of heart failure with normal left ventricular ejection fraction by the heart failure and echocardiography associations of the European Society of Cardiology. Eur Heart J. 2007; 28: 2539-50.
16. Pfeffer M, Swedberg K, Granger C, Held P, McMurray J, Michelson E, et al. Effects of candesartan on mortality and morbidity in patients with chronic heart failure: the CHARM-Overall programme. Lancet. 2003; 362: 759-66.

17. Redfield MM, Jacobsen SJ, Burnett JC Jr, Mahoney DW, Bailey KR, Rodeheffer RJ. Burden of systolic and diastolic ventricular dysfunction in the community: appreciating the scope of the heart failure epidemic. JAMA 2003; 289: 194-202.

18. Owan TE, Hodge DO, Herges RM, Jacobsen SJ, Roger VL, Redfield MM Trends in prevalence and outcome of heart failure with preserved ejection fraction. N Eng J Med. 2006; 355: 251-9.

19. Lenzen MJ, Scholte op Reimer WJ, Boersma E, Vantrimpont PJ, Follath F, Swedberg K, et al. Differences between patients with a preserved and a depressed left ventricular function: a report from the EuroHeart Failure Survey. Eur Heart J. 2004; 25 (14): 1214-20.

20. Peyster E, Norman J, Domanski M. Prevalence and predictors of heart failure with preserved systolic function: community hospital admissions of a racially and gender diverse elderly population. J Card Fail. 2004; 10: 49-54.

21. Aronow WS. Epidemiology, pathophisiology, prognosis, and treatment of systolic and diastolic heart failure. Cardiol Rev. 2006; 14 (3): 108-24.

22. Moutinho MA, Colucci FA, Alcoforado V, Tavares LR, Rachid MB, Rosa ML, et al. Heart failure with preserved ejection fraction and systolic dysfunction in the community. Arq Bras Cardiol. 2008; 90: 132-7.

23. Kass DA, Bronzwaer JG, Paulus WJ. What mechanisms underlie diastolic dysfunction in heart failure? Circ Res. 2004; 94 (12): 1533-42.

24. Hay I, Rich J, Ferber P, Burkhoff D, Maurer MS. Role of impaired myocardia relaxation in the production of elevated left ventricular filling pressure. Am Physiol Heart Circ Physiol. 2005; 288: H1203-H1208.

25. Burkhoff D, Mirsky I, Suga H. Assessment of systolic and diastolic ventricular properties via pressure-volume analysis: a guide for clinical, translational, and basic researchers. Am J Physiol Heart Circ Physiol. 2005; 289: H501-H512.

26. De Stefano LM, Matsubara LS, Matsubara BB. Myocardial dysfunction with increased ventricular compliance in volume overload hypertrophy. Eur J Heart Fail. 2006; 8: 784-9.

27. Borbely A, van der Velden J, Papp Z, Bronzwaer JG, Edes I, Stienen GJ, et al. Cardiomyocyte stiffness in diastolic heart failure. Circulation. 2005; 111: 774-81.

28. Wehrens XH, LehnartSE, Reiken SR, Marks AR. Ca2 +/calmodulin-dependent protein kinase II phosphorylation regulates the cardiac ryanodine receptor. Circ Res. 2004; 94: e61-e70. 


\section{Review Article}

29. Matsubara LS, Matsubara BB, Okoshi MP, Cicogna AC, Janicki JS. Alterations in myocardial collagen affect rat papillary muscle function. Am J Physiol Heart Cic Physiol. 2000; 279: H1534-H1539.

30. Hein S, Amon E, Kostin S, Schönburg M, Elässer A, Polyakova V, et al. Progression from compensated hypertrophy to failure in the pressureoverloaded human heart: structural deterioration and compensatory mechanisms. Circulation. 2003; 107: 984-91.

31. Matsubara LS, Narikawa S, Ferreira ALA, Paiva SAR, Zornoff LAM, Matsubara BB. Remodelação miocárdica na sobrecarga crônica de pressão ou de volume no coração de ratos. Arq Bras Cardiol. 2006; 86: 126-30.

32. Varela-Roman A, Grigorian L, Barge E. Heart failure in patients with preserved and deteriorated left ventricular ejection fraction. Heart. 2005; 91: 489-94.

33. Yancy CW, Lopatin M, Stevenson LW, De Marco T, Fonarow GC. Clinical presentation, management and in-hospital outcomes of patients admitted with acute decompensated heart failure with preserved systolic function. A report from the Acute Decompensated Heart Failure National Registry (ADHERE) Database. J Am Coll Cardiol. 2006; 47: 76-84.

34. Jones RC, Francis GS, Lauer MS. Predictors of mortality in patients with heart failure and preserved systolic function in the Digitalis Investigation Group Trial. J Am Coll Cardiol. 2004; 44: 1025-9.

35. Bhatia RS, Tu JV, Lee DS, Austin PC, Fang J, Haouzi A, et al. Outcome of heart failure with preserved ejection fraction in a population-based study. N Engl J Med. 2006; 355: 260-9.

36. Yamamoto K, Masuyama T, Doi Y, Naito J, Mano T, Kondo H, et al. Noninvasive assessment of $\mathrm{LV}$ relaxation using continuous wave Doppler aortic regurgitant velocity curve: its comparative value to the mitral regurgitation method. Circulation. 1995: 91: 192-200.

37. Honda Y, Yokota Y, Yokoyama M. Evaluation of left ventricular relaxation using the continuous-wave Doppler velocity profile of aortic regurgitation: noninvasive measurement of left ventricular negative $\mathrm{dP} / \mathrm{dt}$ and time constant. Clin Cardiol. 1996; 19: 709-15.

38. Sociedade Brasileira de Cardiologia. III Diretriz brasileira de insuficiência cardíaca crônica. Arq Bras Cardiol. 2009; 93: 1-71.

39. Nagueh SF, Appleton CP, Gillebert TC, Marino PN, Oh JK, Smiseth OA, et al. Recommendations for the evaluation of left ventricular diastolic function by echocardiography. J Am Soc Echocardiogr. 2009; 22 (2): 107-33.

40. Mesquita ET, Jorge AJL. Insuficiência cardíaca com fração de ejeção normal - novos critérios diagnósticos e avanços fisiopatológicos. Arq Bras Cardiol. 2009; 93 (2): 180-7.

41. Little WC, Oh JK. Echocardiographic evaluation of diastolic function can be used to guide clinical care. Circulation. 2009; 120 (9): 802-9.

42. Tshöpe C, Paulus. Is echocardiographic evaluation of diastolic function useful in determining clinical care? Doppler echocardiography yields bubious estimates of left ventricular diastolic pressures. Circulation. 2009; 120 (9): 810-20.

43. Vasan RS, Levy D. Defining diastolic heart failure: a call for standardized diastolic criteria. Circulation. 2000; 101: 2118-21.

44. Zile MR, Gaasch WH, Carroll JD, Feldman MD, Aurigemma GP, Schaer GL, et al. Heart failure with a normal ejection fraction: is measurement of diastolic function necessary to make the diagnosis of diastolic heart failure? Circulation.
$2001 ; 104: 779-82$

45. Yturralde FR, Gaasch WH. Diagnostic criteria for diastolic heart failure. Prog Cardiovasc Dis. 2005; 47: 314-9.

46. Pritchett AM, Mahoney DW, Jacobsen SJ, Rodeheffer RJ, Karon BL, Redfield M. Diastolic dysfunction and left atrial volume. J Am Coll Cardiol. 2005; 45: $87-92$

47. Lester SJ, Tajik J, Nishimura RA, Oh JK, Khandheria BK, Seward JB. Unlocking the mysteries of diastolic function. J Am Coll Cardiol. 2008; 51: 679-89.

48. Clerico A, lervasi G, Del Chicca MG, Emdin M, Maffei S, Nannipieri M, et al. Circulating levels of cardiac natriuretic peptides (ANP and BNP) measured by highly sensitive and specific immunoradiometric assays in normal subjects and in patients with different degrees of heart failure. J Endocrinol Invest. 1998; 21 (3): 170-9.

49. Omland T, Aakvaag A, Bonarjee VVS, Caidahl K, Lie RT, Nilsen DW, et al Plasma brain natriuretic peptide as an indicator of left ventricular systolic function and long-term survival after acute myocardial infarction: comparison with plasma atrial natriuretic peptide and $\mathrm{N}$-terminal proatrial natriuretic peptide. Circulation. 1996; 93 (11): 1963-9.

50. Krishnaswamy P, Lubien E, Clopton P, Koon J, Kazanegra R, Wanner E, et al Utility of B-natriuretic peptide levels in identifying patients with left ventricular systolic or diastolic dysfunction. Am J Med. 2001; 111: 274-9.

51. Yusuf S, Pfeffer MA, Swedberg K, Granger CB, Held P,McMurray J, et al. Effects of candesartan in patients with chronic heart failure and preserved left-ventricular ejection fraction: the CHARM-Preserved Trial. Lancet. 2003; 362: 777-81.

52. Cleland JG, Tendera M, Adamus J, Freemantle N, Polonski L, Taylor J. The perindopril in elderly people with chronic heart failure (PEP-CHF) study. Eur Heart J. 2006; 27: 2238-45.

53. Shibata MC, Flather MD, Böhm M, Borbola J, Cohen-Solal A, Dumitrascu $D$, et al. Study of the effects of nebivolol intervention on outcomes and rehospitalisation in seniors with Heart Failure (SENIORS). Rationale and design. Int J Cardiol. 2002; 86: 77-85.

54. Ahmed A, Rich MW, Fleg JL, Zile MR, Young JB, Kitzman DW, et al. Effects on digoxin on morbitity and mortality in diastolic heart failure: the ancillary digitalis investigation group trial. Circulation. 2006; 114: 397-403.

55. Massie BM, Carson PE, McMurray JJ, Komajda M, McKelvie R, Zile MR. Irbesartan in patients with heart failure and preserved ejection fraction. $\mathrm{N}$ Engl J Med. 2008; 359: 1-12

56. Ren X, Ristow B, Na B, Ali S, Schiller NB, Whooley MA. Prevalence and prognosis of asymptomatic left ventricular diastolic dysfunction ambulatory patients with coronary heart disease. Am J Cardiol. 2007; 99: 1643-7.

57. Yu CM, Lin H, Yang H, Kong SL, Zhang Q, Lee SWL. Progression of systolic abnormalities in patients with "isolated" diastolic heart failures and diastolic dysfunction. Circulation. 2002; 105: 1195-201.

58. Takamura T, Dohi K, Fujimoto N, Kurita T, Kato S. Coupling of left ventricular relaxation to systolic contraction in normal, hypertrophied and dilated myocardium quantified by speckel-tracking global strain and strain rate imaging. Circulation. 2007; 116: 708-9.

59. Yu TT, Wenzelburger F, Lee E, Heatlie G, Leyva F, Patel K, et al. The pathophysiology of heart failure with normal ejection fraction. J Am Coll Cardiol. 2009; 54: 36-46. 